\title{
Atrial septal defect-atrioventricular conduction defects syndrome
}

INSERM

\section{Source}

INSERM. (1999). Orphanet: an online rare disease and orphan drug data base. Atrial septal defect-atrioventricular conduction defects syndrome. ORPHA:1479

Atrial septal defect (ASD) with atrioventricular conduction defects is an extremely rare genetic congenital heart disease characterized by the presence of ASD, mostly of the ostium secundum type (see this term), associated with conduction anomalies like atrioventricular block, atrial fibrillation or right bundle branch block. 